\title{
Henri Lancelot Voisin de La Popelinière, L'Histoire de France. Tome premier (v. 1517-1558)
}

\section{Michele Mastroianni}

\section{(2) OpenEdition}

1 Journals

\section{Edizione digitale}

URL: https://journals.openedition.org/studifrancesi/4649

DOI: 10.4000/studifrancesi.4649

ISSN: 2421-5856

\section{Editore}

Rosenberg \& Sellier

\section{Edizione cartacea}

Data di pubblicazione: 1 avril 2012

Paginazione: 135

ISSN: 0039-2944

\section{Notizia bibliografica digitale}

Michele Mastroianni, «Henri Lancelot Voisin de La Popelinière, L'Histoire de France. Tome premier (v. 1517-1558)», Studi Francesi [Online], 166 (I | LVI) | 2012, online dal 30 novembre 2015, consultato il 19 novembre 2021. URL: http://journals.openedition.org/studifrancesi/4649 ; DOI: https://doi.org/ 10.4000/studifrancesi.4649

Questo documento è stato generato automaticamente il 19 novembre 2021.

\section{(c)}

Studi Francesi è distribuita con Licenza Creative Commons Attribuzione - Non commerciale - Non opere derivate 4.0 Internazionale. 


\title{
Henri Lancelot Voisin de La Popelinière, L'Histoire de France. Tome premier (v. 1517-1558)
}

\author{
Michele Mastroianni
}

\section{NOTIZIA}

HENRI LANCELOT VOISIN DE LA POPELINIÈRE, L'Histoire de France. Tome premier (v. 1517-1558), édition critique par Véronique LARCADE, Pascal RAMBEAUD, Thierry RENTET, Pierre-Jean SOURIAC, Odette TURIAS, sous la direction de Denise TURREL, Genève, Droz, 2011 («Travaux d'Humanisme et Renaissance», n CDLXXXVIII), pp. 591.

1 Ha inizio la pubblicazione, in edizione critica, della monumentale Histoire de France (nella redazione finale del 1581) di La Popelinière, a cura di un'équipe di specialisti, coordinati da Denise Turrel. Il volume che vede ora la luce comprende i primi quattro libri, che coprono una quarantina d'anni, dagli avvenimenti intorno al 1517, soprattutto quelli concernenti lo scoppio della Riforma, fino al 1558. Pur ponendosi come storia generale della Francia del Xvi secolo, l'Histoire di La Popelinière è anzitutto una storia dei troubles religiosi. Protestante, La Popelinière è particolarmente interessato al tema degli scontri confessionali: tuttavia, egli vuole evitare di scrivere una storia di parte ed è fortemente critico nei confronti della politica ugonotta, al punto che il sinodo nazionale delle Chiese riformate riunito nel 1581 a La Rochelle scomunica l'autore dell'Histoire e lo costringe a una pubblica ritrattazione dei suoi errori, condannando a una specie di «indice» protestante quella che senza dubbio è una delle opere più interessanti della storiografia francese cinquecentesca. Nell'introduzione gli editori, in un capitolo breve ma essenziale, ripercorrono la vicenda redazionale dell'Histoire de France del 1581 (su cui è basata la presente edizione), la quale è frutto di un arricchimento progressivo, nel corso degli anni, di quella Vraye et Entiere Histoire che, a partire dall'edizione del 1571, è progressivamente aumentata nelle successive uscite: 
utili tavole di concordanza aiutano a ricostruire lo strutturarsi progressivo di un testo, da considerarsi in elaborazione continua. A Pascal Rambeaud dobbiamo un profilo di La Popelinière (pp. 23-37) che apporta dati interessanti e nuovi: per esempio, lo stabilimento convincente della data di nascita nel 1545 , contro una precedente tradizione. Il testo, edito secondo i criteri acquisiti dalla filologia rinascimentale, è minuziosamente annotato. 